\title{
Karyomorphological Studies in Asiatic Cottons II. Karyotypic analysis of species and races of Asiatic cottons based on nucleolar chromosomes and symmetry of karyotype
}

\author{
M. N. Gennur, A. F. Habib, S. N. Kadapa and J. V. Goud \\ Department of Agricultural Botany, \\ University of Agricultural Sciences, Dharwad, \\ Karnataka 580 005, India
}

Accepted September 28, 1986

In this paper, thorough karyomorphological study has been made covering all the karyotypic details like the number of chromosomes having secondary constriction and satellite; number of median, submedian and subterminal chromosomes; $\mathrm{F} \%$; $\mathrm{TF} \%$; relative length of individual chromosomes and relative length of shortest chromosome.

\section{Materials and methods}

Materials and methods of investigation is the same as in our previous paper "Karyomorphological studies in Asiatic cottons I" except karyotypic parameters which are mentioned below.

F\% and T.F. \% were calculated as given by Huziwara (1962).

$$
\begin{aligned}
& \text { F\%: } \frac{\text { Short arm length of the chromosome }}{\text { Total length of the chromosome }} \times 100 \\
& \text { T.F. } \%: \frac{\text { Total sum of short arm lengths }}{\text { Total sum of chromosome lengths }} \times 100
\end{aligned}
$$

Relative length: $\frac{\text { Chromosome length }}{\text { Absolute length }} \times 100$

Relative length of shortest chromosome $=\frac{\text { Length of shortest chromosome }}{\text { Length of largest chromosome }} \times 100$

(Abbreviations used to specify the type of chromosome: M, median; SM, submedian; ST, subterminal; SC, secondary constriction; S, satellite).

\section{Results and discussion}

The results have been discussed under the headings of nucleolar chromosomes and symmetry of karyotype.

\section{Nucleolar chromosomes}

There was reduction in the number of median secondarily constricted chromosomes from persicum (0.69) to wightianum (0.60) in $G$. herbaceum and from indicum (0.83) to bengalense $(0.14)$ in $G$. arboreum but there was increase in the submedian secondarily constricted chromosomes from persicum (0.69) to wightianum (1.20) and indicum (0.66) to bengalense (0.85) (Table 1).

Number of median satellite chromosomes reduced from persicum (1.30) to wightianum (1.00) in $G$. herbaceum and from indicum $(0.83)$ to bengalense $(0.42)$ in $G$. arboreum but there 


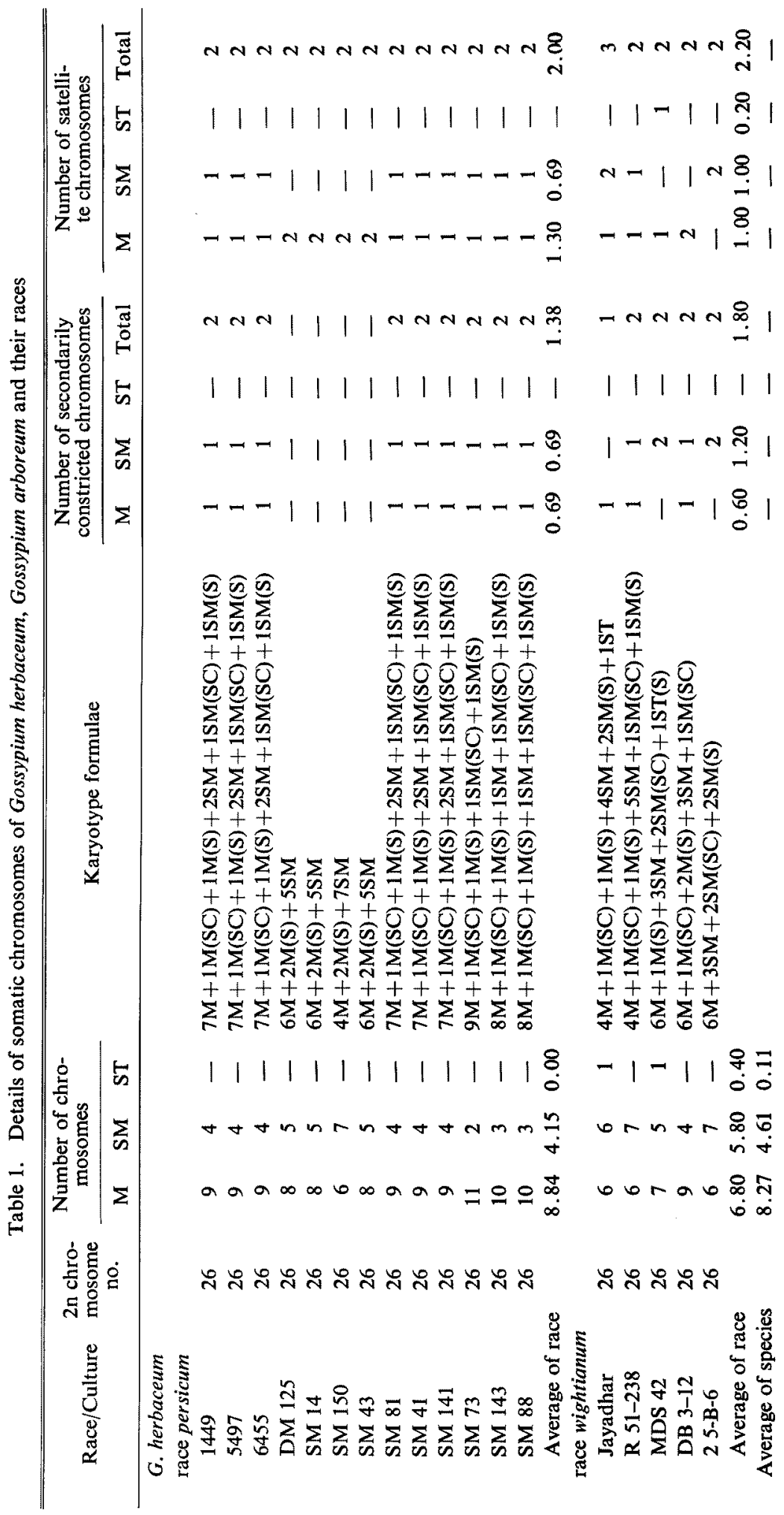




$$
\begin{aligned}
& m N-m-\underset{\infty}{\infty} m N \rightarrow N n m m \underset{\sim}{\infty} \\
& -11111 \frac{0}{0}-1|1| 1|1| \frac{\pi}{0} \\
& n-|N| \text { I }
\end{aligned}
$$

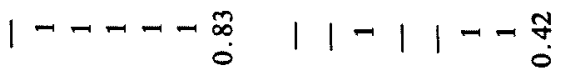

$$
\begin{aligned}
& -4 n-7 n \\
& 1|1| 1|1| 1111111111 \\
& -N|1|-\frac{8}{0}-1 \mid N---\infty \\
& || n--\infty \begin{array}{l}
\infty \\
0
\end{array}||-|||| \frac{\mid}{0} \mid
\end{aligned}
$$

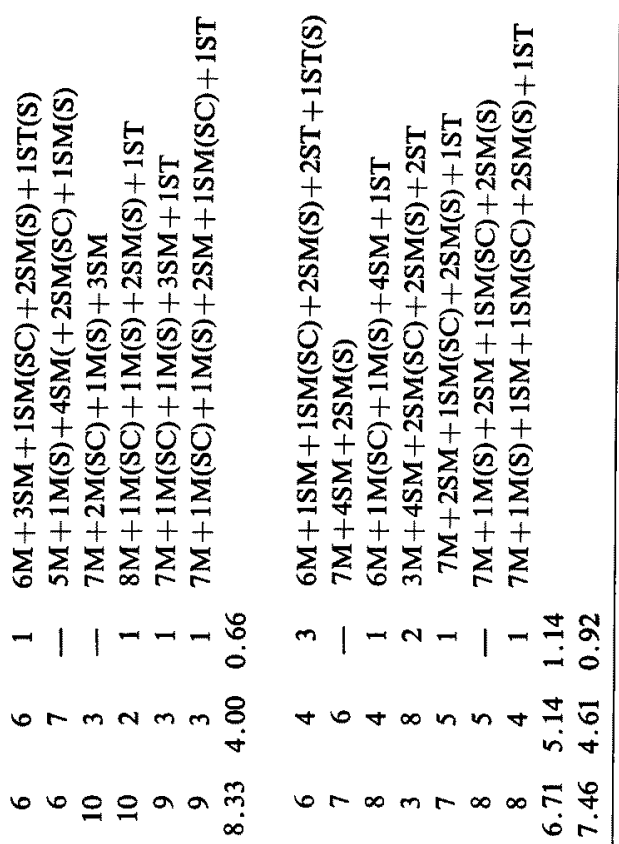

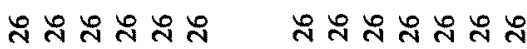

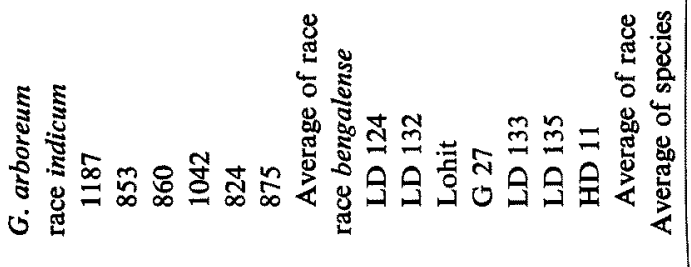


was increase in the submedian satellite chromosomes from persicum (0.69) to wightianum (1.0) and indicum (0.83) to bengalense (1.71) (Table 1).

It confirmed that the modification of median type chromosomes into submedian types had taken place from persicum to wightianum and from indicum to bengalense which would be due to loss of repetitive DNA in the course of evolution. Hence it was considered that wightianum is an advanced race compared to persicum in $G$. herbaceum, and bengalense is advanced race compared to indicum in $G$. arboreum which was in confirmity with the suggestions of Stebbins (1971) in other plant species.

The secondarily constricted chromosomes increased from persicum (1.38) to wightianum (1.80) in G. herbaceum but decreased from indicum (1.50) to bengalense (1.00) in G. arboreum. There was increase in the satellite chromosomes from persicum (2.00) to wightianum (2.20) in G. herbaceum and indicum (1.83) to bengalense (2.28) in G. arboreum (Table 1). It is in agreement with the findings of Stebbins (1950) that the nucleolar organisers might be either lost or gained during evolution.

Jacob's (1942) observation of one pair of satellited and one pair of secondarily constricted chromosomes in the Asiatic cottons was true only in two cultures viz., 824 and Lohit of the present studies. Sikka et al. (1944) and Tutajuk and Sadytiova (1967) observed three pairs of satellited chromosomes in $G$. herbaceum. In the present karyotype analysis of thirty one cultures, fifteen had two pairs of satellited and two pairs of secondarily constricted chromosomes. The remaining cultures had varying number of satellited and secondarily constricted chromosomes (Plate 1 of previous paper i.e. Part I)

\section{Symmetry of karyotype}

In $G$. herbaceum and $G$. arborcum the average number of median, submedian and subterminal chromosomes was $8.27,4.61,0.11$ and $7.46,4.61,0.92$ respectively. In case of $G$. arboreum there was increase in the number of subterminal chromosomes at the expense of median chromosomes compared to $G$. herbaceum. Hence the karyotype of $G$. arboreum was asymmetric compared to $G$. herbaceum. Average number of median, submedian and subterminal chromosomes in persicum and wightianum of $G$. herbaceum was 8.84, 4.15, 0.00 and $6.80,5.80,0.40$ respectively, in indicum and bengalense of $G$. arboreum it was 8.33, 4.00, 0.66 and 6.71, 5.14, 1.14 respectively (Table 1). It was observed that there was increase in the number of pairs of submedian and subterminal chromosomes at the expense of median chromosomes in the race wightianum compared to race persicum of $G$. herbaceum so also in bengalense compared to indicum of $G$, arboreum. Karyotypic analysis with respect to position of centromere also revealed that persicum had no subterminal chromosomes where as two cultures of wightianum (Jayadhar, MDS 42), four cultures of indicum $(1187,1042.824,875)$ and three cultures of bengalense (Lohit, LD 133, HD 11) had one pair of subterminal chromosomes. In bengalense, G 27 and LD 124 had two and three pairs of subterminal chromosomes respectively. Hence there was gradual increase in the number of subterminal chromosome pairs from wightianum to indicum and indicum to bengalense. Therefore, in $G$. herbaceum the race wightianum had asymmetric karyotype compared to that of race presicum, in $G$. arboreum race bengalense had asymmetric karyotype compared to that of race indicum.

For the species $G$. herbaceum and $G$. arboreum the difference in the range of $\mathrm{F} \%$ was 19.13 and 21.95 respectively. For the races persicum and wightianum of $G$. herbaceum the difference in the range of $\mathrm{F} \%$ was 18.44 and 20.93 respectively, for indicum and bengalense of G. arboreum it was 21.14 and 22.64 respectively (Tables 2,3 ). Hence it was observed that at species level G. arboreum had asymmetric karyotype compared to $G$. herbaceum and at racial level wightianum and bengalense had asymmetric karyotypes compared to persicum and indicum respectively in their respective species, since wider range of $\mathrm{F} \%$ indicates asymmetric karyotype (Huziwara 
ㅇํำำㅇำ

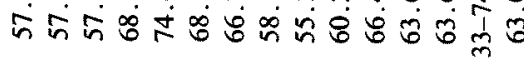
in

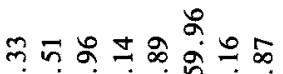

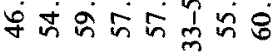

ลิธ์

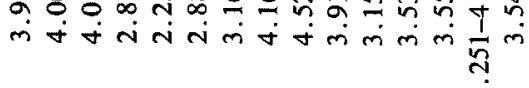

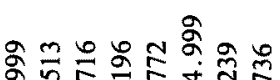

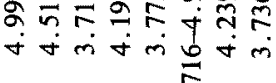

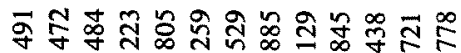
aंa

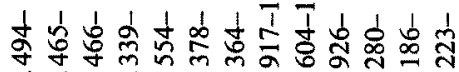

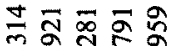

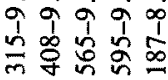
in tin in

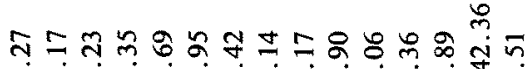

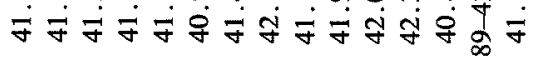
के

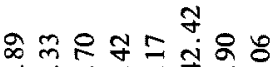

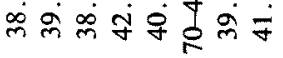
$\infty$

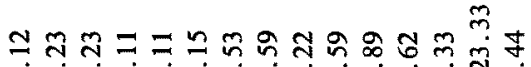

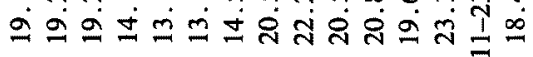

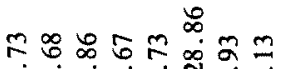
สำำำ

$88888=8888888$

88888

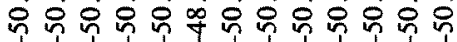

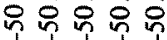

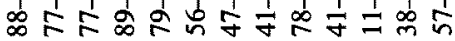
실ㅎํ

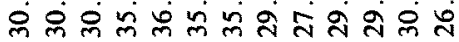
तथ

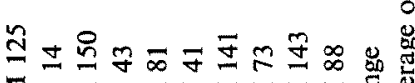

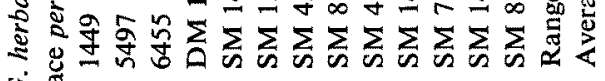

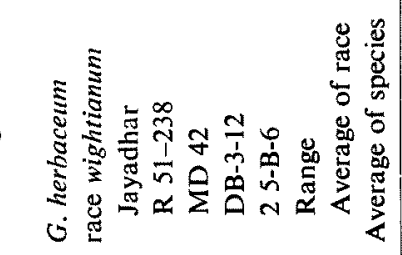




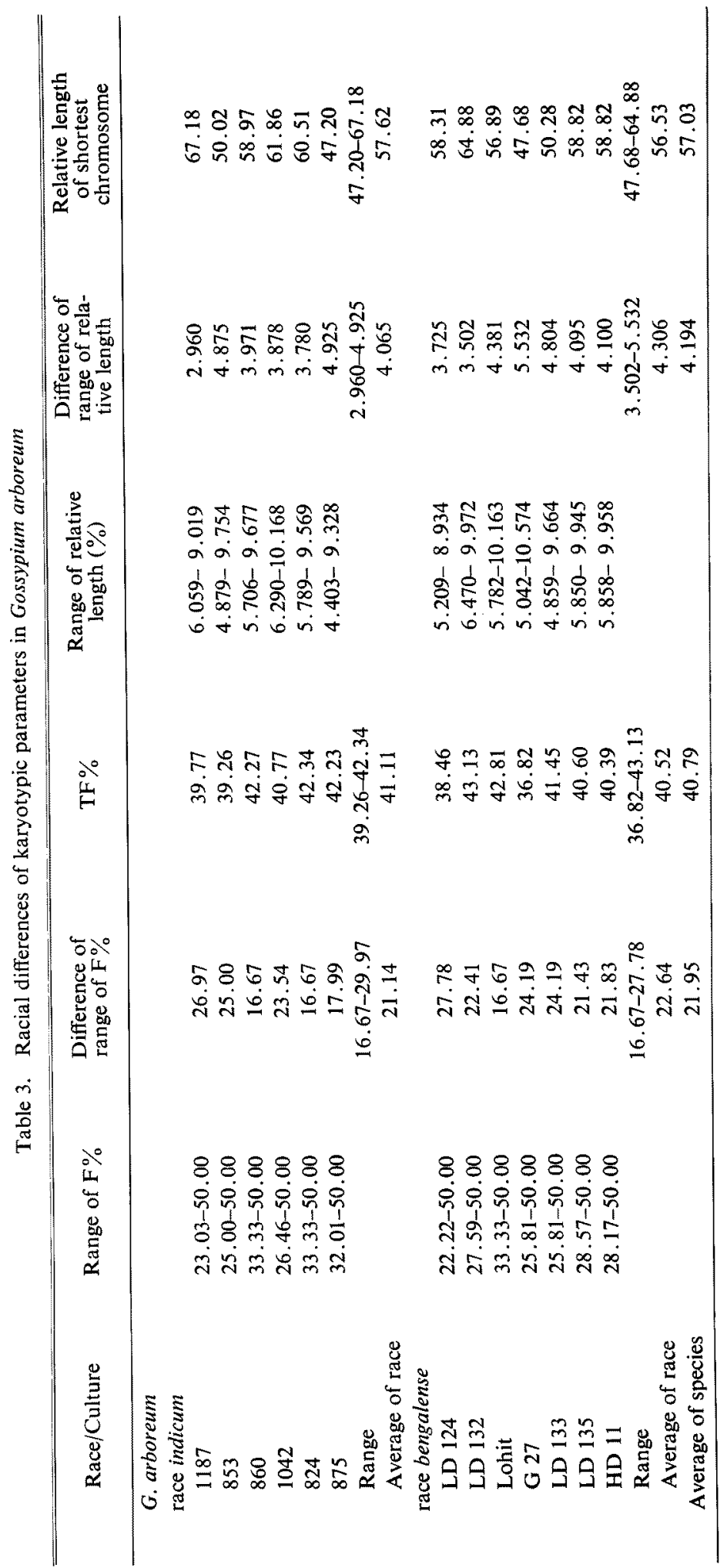


1962). These findings are in line with the observations made by Huziwara (1962) and Sinha and Roy (1979) in Aster and Phaseolus respectively.

In case of $G$. herbaceum and $G$. arboreum $\mathrm{TF} \%$ was $41.06 \%$ and $40.79 \%$ respectively. $\mathrm{TF} \%$ of the race persicum and wightianum was $41.51 \%$ and $39.90 \%$ respectively and that of indicum and bengalense was $41.11 \%$ and $40.52 \%$ respectively (Tables 2,3 ). G. arboreum had asymmetric karyotype compared to G. herbaceum. The race wightianum had asymmetric karyotype compared to persicum in $G$. herbaceum and race bengalense had asymmetric karyotype compared to indicum in $G$. arboreum since lower $\mathrm{TF} \%$ indicates asymmetric karyotype (Huziwara 1962). The study is on par with the studies of Huziwara (1962), Gupta Rani and Gupta (1978) and Sinha and Roy (1979) in Aster, Crotalaria and Phaseolus respectively.

Differences in the range of relative lengths for the species $G$. herbaceum and $G$. arboreum were 3.736 and 4.194 respectively and for the races persicum and wightianum of G. herbaceum it was 3.543 and 4.239 respectively and for the races indicum and bengalense of $G$. arboreum it was 4.065 and 4.306 respectively. $G$. arboreum had the asymmetric karyotype compared to $G$. herbaceum at species level. At racial level race wightianum had asymmetric karyotype compared to race persicum and race bengalense had asymmetric karyotype compared to race indicum since the wider range of relative length is an indication of asymmetric karyotype (Tables 2,3 ).

$G$. arboreum and $G$. herbaceum had the relative lengths of shortest chromosome of $57.03 \%$ and $60.87 \%$ respectively. Relative length of shortest chromosome of race wightianum was lower $(55.16 \%$ ) compared to that of persicum $(63.08 \%)$ in $G$. herbaceum and race bengalense had lower relative length of shortest chromosome $(56.53 \%)$ compared to that of indicum $(57.62 \%)$ in $G$. arboreum. Hence at the species level karyotype of $G$. arboreum was asymmetric compared to $G$. herbaceum and at racial level karyotypes of wightianum and bengalense were asymmetric compared to that of persicum and indicum respectively in their respective species (Tables 2,3 ).

Considering the symmetry of the karyotype it has been concluded that $G$. herbaceum is primitive to $G$. arboreum at species level, and at racial level race persicum is relatively primitive compared to race wightianum in $G$. herbaceum and race indicum is primitive compared to race bengalense in G. arboreum.

Karyotypic analysis with respect to position of centromere, $\mathrm{F} \%, \mathrm{TF} \%$, relative length of individual chromosomes and relative length of shortest chromosome revealed that specialisation of karyotype has taken place as a result of chromosomal repatterning.

The karyotypic change in the process of evolution is from homotypic to heterotypic with the simultaneous change of morphology and habit of the plant i.e., from perennial form to annual forms; since the karyotypic studies of $G$. herbaceum race africanum which is a perennial wild form of Asiatic cottons made by Edwards (1977) revealed that it had no subterminal chromosomes, whereas in the present studies two of the varieties (Jayadhar, MDS 42) of the same species with annual habit had the subterminal chromosomes.

It is in agreement with the observations of Stebbins (1950) that the karyotype of the original unspecialised progenitors of most families of plants was essentially symmetrical and subsequent increased asymmetry of the karyotype in the position of centromeres and relative size of the chromosomes in the course of evolution was the frequent type of change accompanied by increased specialisation in habit and external morphology.

Though two races of $G$. herbaceum did not differ qualitatively they differed very much in quantitative characters. There was lot of variation between two races of $G$. arboreum with respect to qualitative characters apart from quantitative characters (Plate 2, Figs. 8, 9; Plate 3; Table 4 of the previous paper in series). 


\section{Summary}

Karyotypic analysis of Gossypium herbaceum and Gossypium arboreum has been made taking the parameters like number of chromosomes having secondary constriction and satellite, position of centromere i.e. number of median, submedian and subterminal chromosomes, $\mathrm{F} \%$, $\mathrm{TF} \%$, relative length of individual chromosomes and relative length of shortest chromosome. It is concluded that at species level $G$. herbaceum is primitive to G. arboreum and at racial level persicum is primitive to wightianum in $G$. herbaceum, and indicum is primitive to bengalense in G. arboreum.

\section{Acknowledgements}

Senior author is greatful to Shri. S. A. Patil Plant Scientist (Cotton) for his help during investigation.

\section{References}

Edwards, G. A. 1977. The karyotype of Gossypium herbaceum I. Caryologia 30(3) 369-374.

Gupta, Rani and Gupta, P. K. 1978. Karyotype studies in the genus Crotalaria Linn. Cytologia 43: 357-369. Huziwara, Y. 1962. Karyotype analysis in some genera of Compositae VIII. Further studies on the chromosomes of Aster. Amer. J. Bot. 49: 116-119.

Jacob, K. T. 1942. Studies in cotton IV. Morphology of somatic chromosomes in eight types of Asiatic cotton. Trans. Bose Res. Inst. 15: 17-27.

Sikka, S. M., Rahman, I. and Afzal, M. 1944. Study of somatic chromsomes of some wild and cultivated species of Gossypium. Indian J. Genet. Pl. Breed. 4: 55-56.

Sinha, S. S. N. and Roy, H. 1979. Cytological studies in the genus Phaseolus I. Mitotic analysis in fourteen species. Cytologia 44: 191-199.

Stebbins, G. L. 1950. Variation and Evolution in Plants, Oxford Book Company, 458-465.

- 1971. Chromosomal Evolution in Higher Plants. Edward Arnold (publ.) Ltd., London, 49-113.

Tutajuk, V. H. and Sadytiova, L. D. 1967. Morphology of chromosomes in somatic cells of some species of cotton. Meruzeler Azerb. SSR. Elmeler Akad. 23(5) 59-63. 